\title{
ASSIGNMENT OF THE ABSOLUTE CONFIGURATION OF FISCHERIN BY COMPUTED NMR CHEMICAL SHIFTS
}

\author{
S.K. Amini \\ Chemistry and Chemical Engineering Research Center of Iran, Tehran, Iran \\ E-mail: amini_s@ccerci.ac.ir
}

\begin{abstract}
The unassigned configurations of a toxic metabolite to mammals extracted from Neosartorya fischeri (fischerin) in C19, C20, C21, and C22 are assigned as R, R, R, and S, respectively. In this assignment, the extensive ab initio calculations followed by chemical shift computations are performed. Computed chemical shifts are correlated to experimental ones in order to find the correct configuration shown here.
\end{abstract}

DOI: $10.15372 / \mathrm{JSC} 20150714$

K e y w o r d s: configuration, NMR, computational, fischerin, ab initio.

\section{INTRODUCTION}

N-hydroxypyridone derivatives are a bioactive and structurally diverse group of compounds [1]. Some compounds of this group include secondary metabolites in a number of fungi [2]. Fischerin, a biologically active component of fungi, which causes tremors and lethal peritonitis in mice, was extracted from Neosartorya fischeri [ 3 ]. Fujimoto and co-workers reported the partial configuration of fischerin [3 ]. They used NMR spectroscopic data to determine this partial configuration for the fused bicyclic moiety of this compound [3]. As it has been established firmly that NMR spectroscopy is a powerful technique to probe the structure of natural products, and it is used to probe a variety of important structural features of these compounds, they used it to determine the partial configuration of the target molecule. However, despite the use of this powerful technique, Fujimoto and co-workers were not able to assign the relative configurations of the target molecule in C19, C20, C21, and C22 [3 ].

On the other hand, advanced methods in quantum chemistry facilitate the rapid, accurate, and reliable calculation of NMR chemical shifts. So, a comparison of the calculated and experimental chemical shifts will provide an efficient method to identify and discriminate between the proposed diastereoisomers [4]. Therefore, it was interesting to utilize computed ${ }^{1} \mathrm{H}$ and ${ }^{13} \mathrm{C}$ NMR chemical shifts in the assignment of these configurations of the target molecule. This approach, in brief, involved a quantum mechanical treatment of candidate conformers in which geometry optimizations followed by frequency and chemical shielding calculations were employed in order to find a set of computed chemical shifts to compare the experimental ones. This technique has been successfully applied previously for other natural products [4].

Considering the triangular fusion between $\mathrm{C} 20$ and $\mathrm{C} 21$ and the assigned configuration of the fused bicyclic moiety, four unassigned stereocenters allow for totally eight possible diastereomers for the target compound (Fig. 1). In this paper these diastereomers (structures $\mathbf{1}, \mathbf{2}, \mathbf{3}, \mathbf{4}, \mathbf{5}, \mathbf{6}, \mathbf{7}$, and $\mathbf{8}$ ) are also called as 19R-20R-21R-22R, 19R-20R-21R-22S, 19R-20S-21S-22R, 19R-20S-21S-22S, 19S-20R21R-22R, 19S-20R-21R-22S, 19S-20S-21S-22R, and 19S-20S-21S-22S respectively. They were used as probable structures of the target molecule in the quantum mechanical treatments.

(C) Amini S.K., 2015 


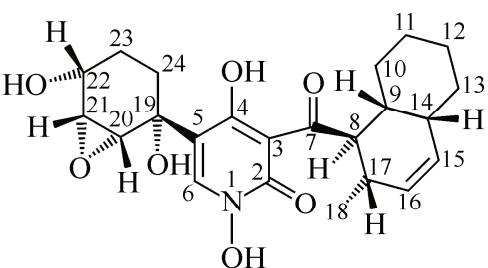

1<smiles>[2H][C@H]1C=C[C@H]2CCCC[C@H]2[C@@H]1C(=O)c1c(O)c([C@]2(O)CC[C@@H](O)[C@H]3O[C@@H]32)cn(O)c1=O</smiles>

4<smiles>O=C(c1c(O)c([C@@H]2CC[C@@H](O)[C@H]3O[C@H]23)cn(O)c1=O)[C@H]1CC=C[C@H]2CCCC[C@H]21</smiles><smiles>C[C@]12CCCC[C@H]1C=CC[C@@H]2C(=O)c1c(O)c([C@]2(O)[CH]C[C@H](O)[C@H]3O[C@@H]32)cn(O)c1=O</smiles>

2

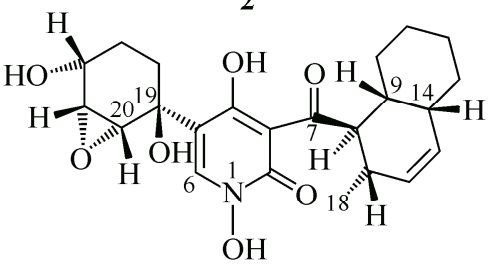

5<smiles>O=C(c1c(O)c([C@@H]2CC[C@@H](O)[C@H]3O[C@H]23)cn(O)c1=O)[C@H]1CC=C[C@H]2CCCC[C@H]21</smiles>

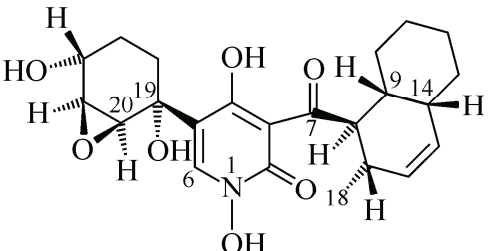

3<smiles>[H][Z13]1([H])C=C[C@H]2CCCC[C@H]2[C@H]1C(=O)c1c(O)c([C@@H]2CC[C@@H](O)[C@H]3O[C@H]23)cn(O)c1=O</smiles>

Fig. 1. Eight diastereomers of the target molecule examined herein

\section{THEORY AND METHODS}

The first step in this treatment was the conformational analysis of probable structures of the target molecule in order to find candidate conformers at room temperature which contribute to the experimental NMR spectra. In this analysis the restricted Hartree-Fock method [ 5-7 ], applying the Gaussian double zeta-split valence basis set [ 8 ] and the RHF/3-21G level of theory, was utilized in order to sample all probable conformers in the gas phase. Since this natural product is rigid to some extent, only some modes of conformational flexibility do exist that should be treated carefully. Due to bulky substituents that occupy equatorial positions, the fused bicyclic moiety could adopt just a single conformation, and any attempt to move these substituents from these positions was accompanied by a very large increase in the energy. On the other hand, owing to the existing fused triangular moiety and bulky substituents, the terminal substituted cyclohexane moiety is approximately rigid and adopts just a single conformation. The six dihedral angles, one controlling the orientation of bicyclic moiety relative to the ketone $\mathrm{C}=\mathrm{O}$ and another controlling the orientation of substituted cyclohexane relative to the pyridone ring, and the other ones controlling the orientations of hydroxyl groups, have approximately $360^{\circ}$ of freedom in all diastereomers (Fig. 2). Thus, six dihedral angles were sampled in order to get candidate conformers which contribute to the observed experimental NMR spectrum at room temperature. In order to sample all possible combinations of all six dihedral angles and to avoid overlapping structures, they were changed either by $60^{\circ}$ or $90^{\circ}$. In the cases where the intramolecular hydrogen bonding was probable, both sides of the surface formed by hydrogen bonding constituents were sampled equally. Of course, most structures with small deviations from the hydrogen bonding geometry were relaxed to structures having this bond at the next step.

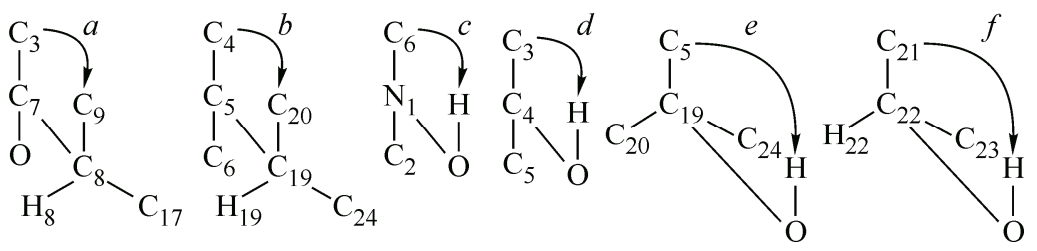

Fig. 2. Six dihedral angles sampled in order to get candidate conformers 
At the next step, considering the Boltzman distribution function $\left(P_{i} / P_{j}\right)=\exp \left(-\left(E_{i}-E_{j}\right) / R T\right)$, where $P_{x}$ and $E_{x}$ are the relative population and the computed free energy of the $x$ conformer, respectively, at $298.15 \mathrm{~K}$, the postulated conformers within a $12.5 \mathrm{~kJ} \cdot \mathrm{mol}^{-1}$ window of the lowest energy, were subjected to the extensive geometry optimization followed by frequency calculations in order to confirm the nature of the optimized geometries as minima and provide their computed free energies. At this step, six, four, six, six, four, six, two, and three conformers were found for structures $\mathbf{1}, \mathbf{2}, \mathbf{3}, \mathbf{4}$, 5, 6, 7, and 8, respectively. Becke's three parameter hybrid functional [9], devised in 1993 using the non-local correlated functional of Lee, Yung and Parr [10,11] with VWN functional III for the local correlation [12] and the Gaussian triple zeta basis set [13] with diffuse [14] and polarization [15] functions, the $\mathrm{B} 3 \mathrm{LYP} / 6-311+\mathrm{G}(d, p)$ level of theory, was used to optimize these candidate structures and calculate their vibrational frequencies both in gas and solution phases.

At the last step, among these extensively optimized structures, those within a $10.5 \mathrm{~kJ} \cdot \mathrm{mol}^{-1}$ window of the lowest energy were subjected to the chemical shielding calculations in the dimethylsulfoxide solvent. This treatment based on the results of the expensive B3LYP/6-311+G $(d, p)$ level of theory, guarantees that eliminated conformers have very little effect on the observed NMR spectra. At this step five, three, five, four, four, six, one, and two conformers were found for structures $\mathbf{1 , 2}, \mathbf{3}, \mathbf{4}$, $\mathbf{5 , 6}, \mathbf{7}$, and $\mathbf{8}$, respectively. Thus, in order to get the accurate calculated chemical shielding values, the Boltzman-weighted averaging based on relative free energies of conformers at $298.15 \mathrm{~K}$ was used. Of course, owing to the fast rotation of methyl groups their computed ${ }^{1} \mathrm{H}$ chemical shielding values were averaged beforehand. For the chemical shielding calculations, the B3LYP/6-311+G $(d, p)$ level of theory was employed as it has reproduced very good results for ${ }^{13} \mathrm{C}$ nuclei under the gauge invariant atomic orbital (GIAO) condition in the previous calculation [ 16, 17].

In all calculations performed in solution, the solvent effects were taken into account using a conductor-like polarizable continuum (CPCM) model for the dimethylsulfoxide solvent [ 18-20 ].

All ab initio conformational analyses, geometry optimization, frequency, and chemical shielding calculations were performed using the G03 package from Gaussian, Inc [21 ].

Calculated chemical shielding values were converted into chemical shift data by plotting these values versus the experimental chemical shifts and using the intercept of the best line as the chemical shielding value of [22 ]. In order to determine the correct configuration of the target molecule, the calculated chemical shifts were evaluated according to their largest and corrected mean absolute deviation (CMAD: [(1/n) $\left.\left.\sum_{i=1}^{n}\left|\delta_{\text {calc }}-\delta_{\text {exp }}\right|\right]\right)$ in each configuration.

In order to confirm the conclusion of the CMAD analysis and get more confidence of which configuration is the correct one, the DP4 probability analysis developed by Smith and Goodman was also employed [4]. The DP4 analysis has been designated especially for the cases in which one set of experimental data is available to which one possible diastereomer out of many can be assigned. The analysis is based on the calculated error probabilities for the computed chemical shift values. It assigns an error probability to each absolute error employing statistical Student's $t$-distribution of the whole set of errors and considering that this error is an independent random variable. Next, Bayes's theorem is applied to get an overall probability by multiplying the probabilities just obtained for each error, indicating that the selected structure is correct from the product of the individual error probabilities for each atom [23]. The final equation is as follows [4]:

$$
P\left(i \mid \delta_{1}, \delta_{2}, \ldots, \delta_{N}\right)=\prod_{k=1}^{N}\left(1-T^{v}\left(\frac{\mid\left(\delta_{\text {calc }, k}^{i}-\delta_{\exp , k}\right)-\mu}{\sigma}\right)\right) / \sum_{j=1}^{m} \prod_{k=1}^{N}\left(1-T^{v}\left(\frac{\left|\left(\delta_{\text {calc }, k}^{j}-\delta_{\exp , k}\right)-\mu\right|}{\sigma}\right)\right) \text {, }
$$

where $P$ is the probability that the $i$ structure is correct among $m$ candidate ones. In this equation, $\mu, \sigma$, and $T^{v}$ are the mean, the standard deviation, and the cumulative $t$-distribution function with $v$ degrees of freedom, respectively [4]. The DP4 analysis is very easy to use, due to a versatile Java applet that the Goodman group has provided [24].

The validity of the CPCM model for the purposes of this paper and of the DP4 analysis for fischerin were investigated using some smaller molecules containing epoxycyclohexane, as in fischerin, in chloroform (a highly polar solvent as well as dimethylsulfoxide). 


\section{RESULTS AND DISCUSSION}

Good agreement was obtained between the experimental data and the calculated chemical shift values of the correct diastereomer of the test molecules in each case [25, 26 ]. This agreement certifies the validity of both CPCM for highly polar solvents and DP4 analysis (DP4 probabilities were more than $98.6 \%$ ).

The calculated chemical shift values of optimized diasteromers and the experimental data of fischerin, both in the dimethylsulfoxide solvent, are summarized in Table 1 [3]. This table includes the largest deviations shown in bold, the calculated CMAD values, and DP4 probabilities.

According to Table 1, good agreement is seen between the experimental chemical shift values of fischerin and the calculated data of structures 2, 7, and 8. From Fig. 1 it is observed for these three structures that the epoxy ring inside the cyclohexane ring is oriented anti relative to the pyridone moiety, which can cause the formation of a more energetically stable diastereomer. The calculated chemical shift values of structures $\mathbf{3}$ - $\mathbf{6}$ show that the syn orientation causes a very large deshielding of C3 (7.0-7.6 ppm) and very large shieldings of C4 and C6 (7.4-10.6 ppm) relative to fischerin [3]. These results reject the syn orientation as the correct one and their opposite trends for the calculated data are acceptable because in the pyridone moiety $\mathrm{C} 3$ is in the meta position relative to epoxycyclohexane, while C4 and C6 are in orto positions. Of course, structure 1 which includes the anti orientation for the epoxy ring and the pyridone moiety obeys the mentioned trends for structures $3-\mathbf{6}$ with 5.5-10.5 ppm of chemical shift deviations. Very large deshieldings of C4 and C6 of syn oriented diastereomers and structure 1 relative to fischerin, are repeated for H6, H21 and H22 (0.6-4.5 ppm). Very large shielding of $\mathrm{C} 3$ of syn oriented diastereomers relative to fischerin is also repeated for $\mathrm{OH} 4$ and H19 (2.0 - $4.9 \mathrm{ppm})$. Thus, it is concluded about fischerin that the epoxy ring inside the cyclohexane ring is oriented anti relative to the pyridone moiety. All diastereomers with the anti orientation show larger deshielding for C19 relative to fischerin (4.2-5.6 ppm), except structure 2 that shows almost the same deshielding as fischerin. According to these deviations, the CMAD value of $2.2 \mathrm{ppm}$ was found for ${ }^{13} \mathrm{C}$ nuclei of structures 2, 7, and $\mathbf{8}$ in comparison to larger values for other structures. Thus, the mentioned conclusion about the anti orientation in fischerin is certified more by both CMAD value and observation that structure 1 with epoxy and pyridone moieties in the anti orientation is the next diastereomer having smaller CMAD values. Slightly better CMAD values were found for ${ }^{1} \mathrm{H}$ nuclei of structure 2 in comparison to two other structures $(0.57 \mathrm{ppm}$ for structure $\mathbf{2}$ in comparison to $0.64 \mathrm{ppm}$ and $0.71 \mathrm{ppm}$ for structures $\mathbf{7}$ and $\mathbf{8}$, respectively). Thus, it is concluded that structure $\mathbf{2}$ (19R-20R-21R-22S diastreomer) is in better agreement with the real configuration of fischerin in

$\mathrm{T}$ a b 1 e 1

Calculated and experimental chemical Shifts accompanying the corresponding CMAD values (ppm) and DP4 probabilities (\%) of optimized diasteromers *

\begin{tabular}{|c|c|c|c|c|c|c|c|c|c|}
\hline \multirow{2}{*}{ Atom } & \multicolumn{8}{|c|}{ Calculated } & \multirow{2}{*}{ Exp.** } \\
\hline & 1 & 2 & 3 & 4 & 5 & 6 & 7 & 8 & \\
\hline 1 & 2 & 3 & 4 & 5 & 6 & 7 & 8 & 9 & 10 \\
\hline \multicolumn{10}{|c|}{${ }^{13} \mathrm{C}$} \\
\hline 2 & 158.0 & 156.7 & 157.9 & 157.9 & 157.0 & 157.6 & 156.3 & 156.4 & 157.9 \\
\hline 3 & 113.5 & 106.4 & 115.1 & 115.2 & 115.0 & 115.6 & 104.9 & 105.0 & 108 \\
\hline 4 & 167.1 & 170.4 & 166.9 & 167.0 & 164.2 & 163.8 & 170.7 & 170.7 & 174.3 \\
\hline 5 & 112.5 & 115.1 & 112.6 & 112.8 & 117.6 & 117.2 & 111.7 & 112.0 & 112.5 \\
\hline 6 & 129.3 & 133.2 & 130.6 & 130.9 & 130.1 & 130.6 & 134.8 & 134.8 & 139.7 \\
\hline 7 & 216.7 & 217.4 & 214.7 & 214.9 & 215.9 & 216.1 & 218.0 & 217.9 & 213.9 \\
\hline 8 & 48.3 & 48.1 & 51.0 & 51.2 & 50.2 & 51.3 & 47.0 & 47.2 & 47 \\
\hline 9 & 40.5 & 40.5 & 34.9 & 35.0 & 34.2 & 35.0 & 38.2 & 38.4 & 37.7 \\
\hline 10 & 25.5 & 27.9 & 26.8 & 27.1 & 25.4 & 26.8 & 27.1 & 27.2 & 29.5 \\
\hline 11 & 18.7 & 20.5 & 18.9 & 19.3 & 17.7 & 18.9 & 19.8 & 20.0 & 21 \\
\hline 12 & 23.9 & 26.0 & 24.9 & 25.2 & 24.6 & 25.4 & 24.0 & 24.3 & 25.7 \\
\hline
\end{tabular}


Continued $\mathrm{Tab}$ e 1

\begin{tabular}{c|r|r|r|r|r|r|r|r|r}
\hline 1 & \multicolumn{1}{c|}{2} & \multicolumn{1}{c|}{3} & \multicolumn{1}{c|}{4} & \multicolumn{1}{c|}{5} & \multicolumn{1}{c|}{6} & \multicolumn{1}{c|}{7} & \multicolumn{1}{c}{8} & \multicolumn{1}{c}{9} & \multicolumn{1}{c}{10} \\
\hline 13 & 28.4 & 30.1 & 29.3 & 29.8 & 28.0 & 29.1 & 28.6 & 28.8 & 28.3 \\
14 & 38.3 & 38.6 & 37.8 & 38.0 & 36.9 & 37.8 & 37.4 & 37.6 & 36.7 \\
15 & 134.6 & 133.9 & 136.0 & 136.2 & 135.9 & 136.0 & 134.3 & 134.4 & 131.1 \\
16 & 135.2 & 133.7 & 136.2 & 136.2 & 135.4 & 135.9 & 133.2 & 133.3 & 131.3 \\
17 & 35.7 & 40.7 & 40.0 & 40.2 & 38.5 & 39.6 & 39.7 & 39.8 & 37.1 \\
18 & 15.3 & 16.2 & 15.7 & 16.1 & 15.4 & 16.6 & 14.4 & 14.6 & 19.3 \\
19 & 73.7 & 69.6 & 76.7 & 77.3 & 69.9 & 71.3 & 72.3 & 72.4 & 68.1 \\
20 & 59.7 & 59.7 & 56.3 & 58.2 & 62.7 & 59.2 & 58.8 & 61.0 & 59.9 \\
21 & 58.7 & 57.5 & 57.9 & 54.9 & 59.3 & 56.3 & 62.1 & 60.0 & 56.8 \\
22 & 68.0 & 65.3 & 65.7 & 62.8 & 66.7 & 65.7 & 64.7 & 62.7 & 65.8 \\
23 & 20.5 & 22.1 & 23.9 & 25.1 & 21.7 & 22.2 & 27.7 & 27.5 & 24.6 \\
24 & 36.0 & 28.5 & 28.2 & 27.0 & 35.4 & 30.0 & 32.5 & 32.0 & 31.8 \\
CMAD & 3.1 & 2.2 & 3.2 & 3.2 & 3.4 & 3.1 & 2.3 & 2.3 & \\
DP4, \% & 0.0 & 76.4 & 0.0 & 0.0 & 0.0 & 0.0 & 6.6 & 17.0 &
\end{tabular}

\begin{tabular}{|l|l|l|l|l|l|l|l|l|}
$\mathrm{DP} 4, \%$ & 0.0 & 76.4 & 0.0 & 0.0 & 0.0 & 0.0 & 6.6 & 17.0
\end{tabular}

\begin{tabular}{c|c|c|c|c|c|c|c|c|c}
\multicolumn{1}{|c|}{${ }^{1} \mathrm{H}$} & \\
6 & 10.39 & 9.09 & 11.32 & $\mathbf{1 1 . 2 6}$ & 12.06 & $\mathbf{1 2 . 4 2}$ & 9.24 & 9.23 & 7.94 \\
8 & 4.74 & 5.40 & 5.03 & 4.95 & 4.85 & 4.92 & 5.40 & 5.34 & 4.93 \\
9 & 2.13 & 2.33 & 2.38 & 2.31 & 2.33 & 2.20 & 2.50 & 2.42 & 2.17 \\
$10 \mathrm{R}$ & 1.31 & 1.43 & 1.57 & 1.46 & 1.47 & 1.26 & 1.52 & 1.44 & 1.66 \\
$10 \mathrm{~S}$ & 0.93 & 1.41 & 1.00 & 0.91 & 1.01 & 0.77 & 1.41 & 1.32 & 1.2 \\
$11 \mathrm{R}$ & 0.43 & 1.18 & 0.72 & 0.64 & 0.48 & 0.21 & 1.34 & 1.26 & 1.29 \\
$11 \mathrm{~S}$ & 0.69 & 1.47 & 2.38 & 2.34 & 2.55 & 2.35 & 1.44 & 1.35 & 1.37 \\
$12 \mathrm{R}$ & 1.32 & 1.68 & 1.49 & 1.44 & 1.41 & 1.15 & 1.85 & 1.78 & 1.6 \\
$12 \mathrm{~S}$ & 0.80 & 1.18 & 0.70 & 0.68 & 0.70 & 0.38 & 1.45 & 1.36 & 1.2 \\
$13 \mathrm{R}$ & 0.71 & 1.27 & 0.75 & 0.65 & 0.62 & 0.37 & 1.34 & 1.27 & 1.37 \\
$13 \mathrm{~S}$ & 1.34 & 1.73 & 1.39 & 1.30 & 1.21 & 1.03 & 1.80 & 1.73 & 1.37 \\
14 & 1.96 & 2.21 & 2.16 & 2.10 & 2.05 & 1.82 & 2.26 & 2.19 & 2.05 \\
15 & 8.06 & 6.61 & 8.37 & 8.28 & 8.38 & 8.79 & 6.54 & 6.51 & 5.64 \\
16 & 7.85 & 6.16 & 7.53 & 7.49 & 7.75 & 7.93 & 6.39 & 6.35 & 5.45 \\
17 & 3.37 & 2.81 & 2.16 & 2.11 & 2.17 & 2.01 & 2.87 & 2.79 & 2.48 \\
18 & 0.41 & 0.85 & 0.15 & 0.09 & 0.10 & -0.25 & 0.97 & 0.88 & 0.92 \\
20 & 4.12 & 3.44 & 3.76 & 3.86 & 3.77 & 3.64 & 3.64 & 3.75 & 3.56 \\
21 & 4.54 & 3.66 & 3.80 & 4.28 & 4.64 & 4.52 & 3.83 & 4.15 & 3.24 \\
22 & 5.12 & 4.64 & 5.05 & 5.17 & 5.63 & 6.07 & 4.32 & 4.50 & 3.94 \\
$23 \mathrm{R}$ & 1.46 & 1.83 & 1.77 & 1.60 & 1.53 & 1.36 & 2.16 & 2.01 & 1.6 \\
$23 \mathrm{~S}$ & 1.178 & 1.55 & 1.00 & 1.16 & 1.06 & 1.20 & 1.47 & 1.52 & 1.08 \\
$24 \mathrm{R}$ & 1.077 & 1.22 & 1.00 & 1.22 & 1.73 & 1.44 & 1.82 & 1.51 & 1.45 \\
$24 \mathrm{~S}$ & 2.12 & 2.37 & 1.81 & 1.60 & 1.92 & 1.56 & 1.62 & 1.87 & 2.22 \\
$\mathrm{OH} 1$ & 13.38 & 10.31 & 13.56 & 13.55 & 13.89 & 14.54 & 10.50 & 10.47 & 11.74 \\
$\mathrm{OH} 4$ & 14.34 & 17.96 & 14.35 & 14.27 & 14.18 & 12.62 & 18.29 & 18.06 & 16.98 \\
$\mathrm{OH} 19$ & 4.22 & 3.14 & 2.59 & 2.255 & $\mathbf{0 . 4 4}$ & 3.39 & 1.61 & $\mathbf{1 . 5 5}$ & 5.34 \\
$\mathrm{OH} 22$ & $\mathbf{0 . 6 6}$ & $\mathbf{1 . 7 2}$ & $\mathbf{0 . 8 6}$ & 1.67 & 0.73 & 0.95 & $\mathbf{1 . 0 7}$ & 2.02 & 4.85 \\
$\mathrm{CMAD}$ & 0.96 & 0.57 & 1.00 & 1.01 & 1.20 & 1.30 & 0.71 & 0.64 & \\
$\mathrm{DP} 4, \%$ & 0.0 & 100.0 & 0.0 & 0.0 & 0.0 & 0.0 & 0.0 & 0.0 & \\
& & & & & & & & & \\
14 &
\end{tabular}

$$
\begin{array}{c|c|c|c|c|c}
\mathrm{DP} 4, \% & 0.0 & 100.0 & 0.0 & 0.0 & 0.0 \\
{ }^{13} \mathrm{C}+{ }^{1} \mathrm{H}
\end{array}
$$

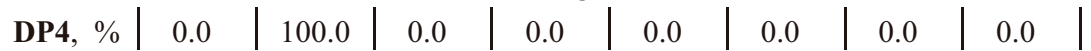

* Largest deviations for each set of data are highlighted in bold.

** From [3]. 
Fig. 3. Correct three dimensional structures of fischerin (19R-20R-21R-22S)

comparison to all other diastereomers. Its largest deviations are only $6.5 \mathrm{ppm}$ and $3.13 \mathrm{ppm}$ for ${ }^{13} \mathrm{C}$ and ${ }^{1} \mathrm{H}$ nuclei, respectively, in comparison to much larger deviations obtained for other diastereomers. Finally, it seems difficult to rely completely upon the CMAD values because not only differences among all CMAD values are

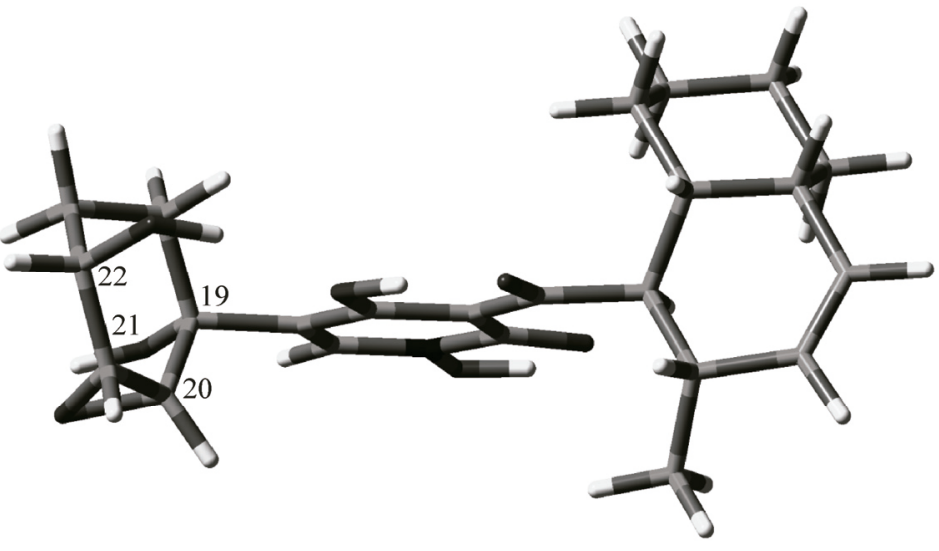
small, but also structures $\mathbf{2}, \mathbf{7}$, and $\mathbf{8}$ produce almost the same values. Thus, for more confidence, a more precise analysis should be taken into account and it was decided to resort on the DP4 probability analysis.

Analyzing DP4 probabilities, we see that all structures, except structures $\mathbf{2 ,} \mathbf{7}$, and $\mathbf{8}$, have zero probabilities considering ${ }^{13} \mathrm{C}$ nuclei. Since according to the DP4 analysis an increase in a deviation of a calculated chemical shift value will result in a large reduction in its occurrence probability, zero probabilities for the calculated ${ }^{13} \mathrm{C}$ chemical shift values of structure $\mathbf{1}$ and structures $\mathbf{3}-\mathbf{6}$ are related to their very large deviations such as chemical shift values of $\mathrm{C} 3, \mathrm{C} 4, \mathrm{C} 6$. Also small probabilities for ${ }^{13} \mathrm{C}$ chemical shift values of structures $\mathbf{7}$ and $\mathbf{8}$ are related to their large deviations such as chemical shift values of $\mathrm{C} 3, \mathrm{C} 4, \mathrm{C} 6, \mathrm{C} 19, \mathrm{C} 21$, and $\mathrm{C} 23$. Although structures $\mathbf{2}, \mathbf{7}$, and $\mathbf{8}$ have appreciable probabilities considering just ${ }^{13} \mathrm{C}$ nuclei, but these probabilities become zero for structures 7 and 8 , considering either ${ }^{1} \mathrm{H}$ or ${ }^{1} \mathrm{H}+{ }^{13} \mathrm{C}$ nuclei. Zero probabilities for ${ }^{1} \mathrm{H}$ chemical shift values of all structures, except structure $\mathbf{2}$, are related to their very large deviations such as chemical shift values of H6, H21, H22, OH4, and $\mathrm{OH} 22$. Thus, the DP4 analysis strongly proposes structure $\mathbf{2}$ as the correct one for the target molecule, which is in accordance with the CMAD analysis (Fig. 3). The DP4 probability of this structure is $76.4 \%, 100.0 \%$, and $100.0 \%$ considering carbon, hydrogen and both of them, respectively.

Since different configurations around stereocenter nuclei affect absolute deviations in the bond and the steric vicinity of these centers more than other ones, the conclusion about the correct configuration is more confirmed by a comparison of those of structures $\mathbf{1}-\mathbf{8}$, reported in Table 2. The deviations highlighted in bold in this table are larger than $4.0 \mathrm{ppm}$ and $1.0 \mathrm{ppm}$ for ${ }^{13} \mathrm{C}$ and ${ }^{1} \mathrm{H}$ nuclei, re-

$\mathrm{T}$ a b 1 e 2 Absolute deviations (ppm) of ${ }^{13} \mathrm{C}$ and ${ }^{1} \mathrm{H}$ nuclei in the vicinity of the unassigned stereocenters of structures $1-\mathbf{8}^{*}$

\begin{tabular}{|c|c|c|c|c|c|c|c|c|c|c|c|c|c|c|c|c|c|}
\hline Atom & 1 & 2 & 3 & 4 & 5 & 6 & 7 & 8 & Atom & 1 & 2 & 3 & 4 & 5 & 6 & 7 & 8 \\
\hline \multicolumn{9}{|c|}{${ }^{13} \mathrm{C}$} & \multicolumn{9}{|c|}{${ }^{1} \mathrm{H}$} \\
\hline 2 & 0.10 & 1.16 & 0.01 & 0.01 & 0.93 & 0.32 & 1.60 & 1.49 & 6 & 2.45 & 1.15 & 3.38 & 3.32 & 4.12 & 4.48 & 1.30 & 1.29 \\
\hline 3 & 5.47 & 1.60 & 7.07 & 7.15 & 7.01 & 7.58 & 3.07 & 3.03 & 20 & 0.56 & 0.12 & 0.20 & 0.30 & 0.21 & 0.08 & 0.08 & 0.19 \\
\hline 4 & 7.20 & 3.93 & 7.39 & 7.35 & 10.09 & 10.55 & 3.56 & 3.59 & 21 & 1.30 & 0.42 & 0.56 & 1.04 & 1.40 & 1.28 & 0.59 & 0.91 \\
\hline 5 & 0.03 & 2.58 & 0.12 & 0.31 & 5.13 & 4.66 & 0.81 & 0.53 & 22 & 1.18 & 0.70 & 1.11 & 1.23 & 1.69 & 2.13 & 0.38 & 0.56 \\
\hline 6 & 10.42 & 6.54 & 9.12 & 8.84 & 9.56 & 9.13 & 4.93 & 4.87 & 23 & 0.14 & 0.23 & 0.17 & 0.00 & 0.07 & 0.24 & 0.56 & 0.41 \\
\hline 19 & 5.61 & 1.46 & 8.64 & 9.20 & 1.78 & 3.19 & 4.16 & 4.29 & 23 & 0.10 & 0.47 & 0.08 & 0.08 & 0.02 & 0.12 & 0.39 & 0.44 \\
\hline 20 & 0.18 & 0.25 & 3.59 & 1.74 & 2.84 & 0.74 & 1.12 & 1.15 & 24 & 0.37 & 0.23 & 0.45 & 0.23 & 0.28 & 0.01 & 0.37 & 0.06 \\
\hline 21 & 1.90 & 0.68 & 1.08 & 1.89 & 2.52 & 0.48 & 5.30 & 3.20 & 24 & 0.10 & 0.15 & 0.41 & 0.62 & 0.30 & 0.66 & 0.60 & 0.36 \\
\hline 22 & 2.24 & 0.45 & 0.08 & 3.03 & 0.87 & 0.06 & 1.15 & 3.08 & $\mathrm{OH} 1$ & 1.64 & 1.43 & 1.82 & 1.81 & 2.15 & 2.80 & 1.24 & 1.27 \\
\hline 23 & 4.10 & 2.52 & 0.68 & 0.53 & 2.92 & 2.44 & 3.06 & 2.93 & $\mathrm{OH} 4$ & 2.64 & 0.98 & 2.63 & 2.71 & 2.80 & 4.36 & 1.31 & 1.08 \\
\hline \multirow[t]{2}{*}{24} & 4.17 & 3.35 & 3.60 & 4.79 & 3.59 & 1.76 & 0.68 & 0.23 & OH19 & 1.12 & 2.20 & 2.75 & 3.09 & 4.90 & 1.95 & 3.73 & 3.79 \\
\hline & & & & & & & & & OH22 & 4.19 & 3.13 & 3.99 & 3.18 & 4.12 & 3.90 & 3.78 & 2.83 \\
\hline
\end{tabular}

* Larger deviations for each set of data are highlighted in bold. 
spectively. As the whole outputs of the DP4 analyses show, these large deviations result in several probabilities smaller by an order of magnitude for the relevant configurations. By a good approximation, their plurality and absolute values for each configuration relative to the others, can determine the relative probability of that configuration regardless of other deviations.

It is seen that minimum deviations of most nuclei occur for structure 2 . When this trend is not met, this structure provides small differences in comparison to the minimum deviations. On the other hand anywhere the data on this structure have been bolded, data on all other structures have been bolded, too. It is seen that their bolded values are much larger than those of this structure, except just several cases in which the bolded data on this structure are the same. Especially, it is seen that this conclusion is met for the stereocenter carbon nuclei and for the hydrogen nuclei directly bonded to these stereocenters. Thus, very large bolded values in the bond and steric vicinity of configurationally incorrect assigned stereocenters of the other structures confirm that they are not the correct structure of the target molecule.

\section{CONCLUSIONS}

In this brief study the unassigned configurations of fischerin, extracted from Neosartorya fischeri, at C19, C20, C21, and C22 were assigned as R, R, R, and S, respectively. In this assignment the extensive conformational analysis and the geometry optimization followed by frequency and chemical shielding calculations were employed in order to get the best computed chemical shifts as compared to the experimental ones. This conclusion was a result of both CMAD and DP4 analyses which produce smaller deviations and larger probabilities for the structure.

The author acknowledges Prof. Alex D. Bain (McMaster University) for his instructive comments.

\section{REFERENCES}

1. Cheng M., Yan L., Shubin N., Hua Zh., Xingzhong L., Yongsheng Ch. // J. Nat. Prod. - 2011. - 74. - P. 32.

2. Halo L.M., Heneghan M.N., Yakasai A.A., Song Zh., Williams K., Bailey A.M., Cox R.J., Lazarus C.M., Simpson T.J. // J. Am. Chem. Soc. - 2008. - 130. - P. 17988.

3. Fujimoto H., Ikeda M., Yamamoto K., Yamazaki M. // J. Nat. Prod. - 1993. - 56. - P. 1268.

4. Smith S.G., Goodman J.M. // J. Am. Chem. Soc. - 2010. - 132. - P. 12946 and references therein.

5. Pople J.A., Nesbet R.K. // J. Chem. Phys. - 1954. - 22. - P. 571.

6. Roothaan C.C. // Rev. Mod. Phys. - 1951. - 23. - P. 69.

7. McWeeny R., Dierksen G. // J. Chem. Phys. - 1968. - 49. - P. 4852.

8. Binkley J.S., Pople J.A., Hehre W.J. // J. Am. Chem. Soc. - 1980. - 102. - P. 939.

9. Becke A.D. // J. Chem. Phys. - 1993. - 98. - P. 5648.

10. Lee C., Yang W., Parr R.G. // Phys. Rev. B. - 1988. - 37. - P. 785.

11. Miehlich B., Savin A., Stoll H., Preuss H. // Chem. Phys. Lett. - 1989. - 157. - P. 200.

12. Vosko S.H., Wilk L., Nusair M. // Can. J. Phys. - 1980. - 58. - P. 1200.

13. Ditchfield R., Hehre W.J., Pople J.A. // J. Chem. Phys. - 1971. - 54. - P. 724.

14. Clark T., Chandrasekhar J., Spitznagel G.W., Schleyer P.V.R. // J. Comput. Chem. - 1983. - 4. - P. 294.

15. Frisch M.J., Pople J.A., Binkley J.S. // J. Chem. Phys. - 1984. - 80. - P. 3265.

16. Amini S.K., Shaghaghi H., Bain A.D., Chabok A., Tafazzoli M. // Solid State Nucl. Magn. Reson. - 2010. - 37. - P. 13.

17. Ditchfield R. // Mol. Phys. - 1974. - 27. - P. 789.

18. Klamt A., Schurmann G. // J. Chem. Soc., Perkin Trans. - 1993. - 2. - P. 799.

19. Andzelm J., Kolmel C., Klamt A. // J. Chem. Phys. - 1995. - 103. - P. 9312.

20. Barone V., Cossi M. // J. Phys. Chem. A. - 1998. - 102. - P. 1995.

21. Frisch M.J., Trucks G.W., Schlegel H.B., Scuseria G.E., Robb M.A., Cheeseman J.R., Zakrzewski V.G., Montgomery J.A., Stratmann R.E. Jr., Burant J.C., Dapprich S., Millam J.M., Daniels A.D., Kudin K.N., Strain M.C., Farkas M.C., Tomasi J., Barone V., Cossi M., Cammi R., Mennucci B., Pomelli C., Adamo C., Clifford S., Ochterski J., Petersson G.A., Ayala P.Y., Cui Q., Morokuma K., Malick D.K., Rabuck A.D., Raghavachari K., Foresman J.B., Cioslowski J., Ortiz J.V., Baboul A.G., Stefanov B.B., Liu G., Liashenko A., Piskorz P., Komaromi I., Gomperts R., Martin R.L., Fox D.J., Keith T., Al-Laham M.A., Peng C.Y., Nanayakkara A., Gonzalez C., Challacombe M., Gill P.M.W., Johnson B.G., Chen W., Wong M.W., Andres J.L., Head-Gordon M., Replogle E.S., Pople J.A. Gaussian 03, Revision C.02, Gaussian Inc., Wallingford CT, 2004.

22. Harris R.K. Nuclear Magnetic Resonance (A Physical View), Longman Scientific \& Technical, Hong Kong, 1986.

23. Riley K.F., Hobson M.P., Bence S.J. Mathematical Methods for Physics, Engineering. - Cambridge: Cambridge University Press, 2006.

24. http: // www-jmg.ch.cam.ac.uk/tools/nmr/nmrParameters.html.

25. Washington I., Houk K.N. // Angew. Chem. Int. Ed. - 2001. - 40. - P. 4485.

26. Honda T., Endo K. // J. Chem. Soc., Perkin Trans. - 2001. - 1. - P. 2915. 